\title{
Política de expansão das licenciaturas em Educação do Campo: desafios para a implantação do Programa Nacional de Educação do Campo na Universidade Federal de Mato Grosso do Sul ${ }^{\mathrm{i}}$
}

\author{
Jorge Luis D'Ávila ${ }^{1}$ \\ ${ }^{1}$ Universidade Federal de Mato Grosso do Sul - UFMS. Faculdade de Educação. Avenida Costa e Silva s/n. Campo Grande - \\ MS. Brasil. \\ Autor para correspondência/Author for correspondence: davilajorgeluis35@gmail.com
}

\begin{abstract}
RESUMO. O texto busca analisar o processo de implantação do curso de Licenciatura em Educação do Campo da Universidade Federal de Mato Grosso do Sul, na perspectiva de compreender a morosidade do Estado brasileiro na execução da gestão das políticas educacionais. Para tanto, se leva em consideração as articulações recíprocas entre Estado, educação e educação do campo, na perspectiva marxiana. Nosso pressuposto de análise parte da totalidade das relações entre os homens, o que nos permite reintegrar nessa totalidade a base material e a base política do mundo dos homens. A política de formação de professores do campo é uma ação do Estado que pretende amenizar as pressões e as demandas apresentadas pelos movimentos sociais ligados à luta pela reforma agrária. A expansão da licenciatura em foco esbarra nas políticas de caráter neoliberais que reduzem as verbas destinadas à expansão dos cursos, o que afeta diretamente a autonomia das universidades e os fatores ideológicos decorrentes das características pedagógicas do curso, que tem na luta de classes o seu principal ponto de reflexão como outro entrave para a expansão da LEDUCAMPO.
\end{abstract}

Palavras-chave: Políticas Educacionais, Educação do Campo, Estado. 


\title{
Policy of expansion of Undergraduate Course in Rural Education: Challenges for the implementation of the National Program of Education of the countryside in the Federal University of Mato Grosso do Sul
}

\begin{abstract}
This text seeks to analyze the process of implementation of the Undergraduate Course in Rural Education of the Federal University of Mato Grosso do Sul, in order to understand the slowness of the Brazilian State in the execution of the management of educational policies. In order to do so, one takes into account the reciprocal articulations between state, education and rural education, in the Marxian perspective. Our analysis presupposes the totality of relationships between men, which allows us to reintegrate into this totality the material basis and political basis of the world of men. The policy of training teachers in the countryside is an action of the State that seeks to soften the pressures and demands presented by social movements linked to the struggle for agrarian reform. The expansion of the bachelor's degree focuses on the neoliberal policies that reduce the funds destined to the expansion of the courses, which directly affects the autonomy of the universities and the ideological factors arising from the pedagogical characteristics of the course, which has in the class struggle its main point is another obstacle to the expansion of LEDUCAMPO.
\end{abstract}

Keywords: Educational Policies, Rural Education, State. 


\section{Política de expansión de las licenciaturas en Educación del Campo: desafíos para la implantación del Programa Nacional de Educación del Campo en la Universidad Federal de Mato Grosso do Sul}

RESUMEN. El texto busca analizar el proceso de implantación del curso de Licenciatura en Educación del Campo de la Universidad Federal de Mato Grosso do Sul, en la perspectiva de comprender la morosidad del Estado brasileño en la ejecución de la gestión de las políticas educativas. Para ello, se tiene en cuenta las articulaciones recíprocas entre Estado, educación y educación del campo, en la perspectiva marxiana. Nuestro supuesto de análisis parte de la totalidad de las relaciones entre los hombres, lo que nos permite reintegrar en su totalidad la base material y la base política del mundo de los hombres. La política de formación de profesores del campo es una acción del Estado que pretende amenizar las presiones y las demandas presentadas por los movimientos sociales ligados a la lucha por la reforma agraria. La expansión de la licenciatura en foco tropieza en las políticas de carácter neoliberales que reducen los fondos destinados a la expansión de los cursos, lo que afecta directamente la autonomía de las universidades y los factores ideológicos derivados de las características pedagógicas del curso, que tiene en la lucha de clases su principal punto de reflexión como otro obstáculo para la expansión de la LEDUCAMPO.

Palabras clave: Políticas Educativas, Educación del Campo, Estado. 


\section{Introdução}

O objetivo deste artigo é analisar o processo de implantação do curso de Licenciatura em Educação do Campo (LEDUCAMPO) da Universidade Federal de Mato Grosso do Sul (UFMS) na expectativa de compreender a morosidade do Estado brasileiro na execução da gestão das políticas educacionais, em especial a de formação de professores do campo.

O texto tem como fonte de estudo os editais e portarias elaborados pelo Ministério da Educação (MEC) que permitiram a criação por parte da UFMS da Leducampo, o Projeto PolíticoPedagógico do curso em questão, as ATAS produzidas pelo colegiado do curso e o Plano de Trabalho Anual (PTA). Para que tais documentos nos revelem os fatos e intenções concretas do Estado brasileiro no que se refere à formação de professores do campo se faz necessário estabelecer conexões entre os diversos interesses de classe, levando em consideração as articulações recíprocas entre Estado, educação e Educação do Campo, na perspectiva marxiana o que nos permite compreender a realidade social histórica, as condições materiais da produção humana, suas contradições e determinações da totalidade da sociabilidade vigente. Nesse viés o objeto é visto "como parte de uma totalidade histórica que o constitui, onde se estabelecem as mediações entre o campo da particularidade e sua relação com uma determinada universalidade" (Frigotto, 2010, p. 2).

Entendemos assim como Palumbo (1994, p. 38) que o termo políticas públicas é o “... princípio norteador por trás de regulamentos, leis e programas; sua manifestação visível é a estratégia adotada pelo governo para solucionar os problemas públicos". Contudo, uma política não é um processo linear, mas algo que se encontra em constante movimento, isto é, tem que ser “... inferida a partir de uma série de ações e comportamento intencionais de muitas agências e funcionários governamentais envolvidos na execução da política ao longo do tempo" (Palumbo, 1994, p. 35). Portanto, uma política pública não pode ser discernida tendo-se em conta apenas um evento ou uma ação. Deve ser vista como uma categoria analítica utilizada por pesquisadores para estudar as estratégias governamentais por certo período.

\section{Desafios para a manutenção e ampliação da LEDUCAMPO}

$\mathrm{O}$ referido curso começou a ser planejado no ano de 2013, em resposta à chamada do Ministério de Educação (MEC), por meio de ação integrada entre: Secretaria de Educação Superior; Secretaria de Educação Continuada, 
Alfabetização, Diversidade e Inclusão; Secretaria de Educação Profissional e Tecnologia, mediante Edital n. 2 SESU/SETEC/SECADI/MEC, de 31 de agosto de 2012, publicado no Diário Oficial da União de 05 de setembro de 2012. Este Edital tinha como previsão a implantação de 40 cursos regulares de Licenciatura em Educação do Campo que atendesse no mínimo 120 alunos por ano, com um aporte de recursos financeiros específicos em um período de três anos e também visava à ampliação do número de vagas para os cursos já existentes.

O Movimento da Educação do Campo está ancorado na primeira Conferência Nacional por Uma Educação Básica do Campo (CNEC), realizada em 1998 e na segunda Conferência em 2004 cujo lema era "Por Um Sistema Público de Educação do Campo". Com isso, o MEC elaborou um plano piloto que teve como executoras: A Universidade Federal de Minas Gerais (UFMG), Universidade de Brasília (UNB), Universidade Federal da Bahia (UFBA) e Universidade Federal de Sergipe (UFS).

De acordo com Molina (2015), as Instituições Federais de Ensino Superior (IFES) citada foram convidadas a fazerem parte desse plano devido as suas experiências na gestão pedagógica da educação do campo e, também, por terem . relação com os movimentos sociais e sindicais envolvidos nos conflitos agrários. Cabe ponderar que os outros cursos de licenciatura do campo que foram ofertados pelas Universidades Federais até o ano de 2016 não tinham esse vínculo, como é o caso da UFMS.

A graduação em educação do campo deve ter duração de quatro anos na modalidade presencial, tendo a Pedagogia da Alternância ${ }^{\text {ii }}$ como metodologia. Esta consiste na articulação entre o Tempo Universidade (TU) onde os alunos permanecem o período de aula na Universidade e Tempo Comunidade (TC) ocorre no momento em que os acadêmicos retornam às suas propriedades familiares ou às comunidades ou aos assentamentos para colocarem em prática aquilo que foi proposto no TU. Essa forma de organização atende ao Programa de Apoio à Formação Superior em Licenciatura em Educação do Campo (PROCAMPO).

Cabe considerar que a política de formação de professores do campo é uma ação do Estado que pretende amenizar as pressões e as demandas apresentadas pelos movimentos sociais ligados à luta pela reforma agrária com o intuito de superar o pensamento de que o docente deve ser formado para “... desenvolver os mesmos saberes e competências do ensino fundamental, independentemente da diversidade de coletivos humanos" (Arroyo, 2012, p. 361). 
Superar esse modelo de formação implica em mudanças de práticas burguesas que privilegiam a formação urbana e acreditam que os povos e escolas do campo encontram em um processo de extinção, que incentiva o transporte de alunos do campo para estudarem nas escolas urbanas e direcionam docentes urbanos para trabalhar no campo sem que os mesmos tenham vínculo com a cultura e os saberes dos moradores do campo (Arroyo, 2012).

Arroyo (2012) pondera que o processo de formulação da política de formação de professores do campo não segue os mesmos padrões de planejamento das outras políticas que veem os setores populares apenas como destinatários, mas sim, como autores-sujeitos que têm uma participação efetiva no planejamento das políticas de formação docente. Essa participação implica em “... tensões não apenas nas concepções de formação, mas tensões políticas de reconhecimento dos movimentos sociais como autores nas universidades, no MEC e nos órgãos de formulação e análise de políticas do Estado" (Arroyo, 2012, p. 362).

Segundo o Fórum Nacional de Educação do Campo (FONEC), a política formação de professores do campo foi materializada em um período de transição conhecido como "da crise do latifúndio a . consolidação do Agronegócio", momento em que a burguesia latifundiária passava por ajustes econômicos. Desta forma, é possível afirmar que a licenciatura em educação do campo ocupou,

$$
\begin{aligned}
& \text {.. um "vácuo" de transição de } \\
& \text { modelos (ajustes no modelo macro- } \\
& \text { econômico brasileiro, capitalista, } \\
& \text { neoliberal): entre a crise do latifúndio } \\
& \text { e a emergência do agronegócio os } \\
& \text { movimentos sociais de luta pela terra } \\
& \text { e pela Reforma Agrária ganharam } \\
& \text { ímpeto, conquistaram o Pronera e } \\
& \text { constituíram a Educação do Campo. } \\
& \text { A nova fase na política do capital } \\
& \text { para a agricultura, que iniciou com } \\
& \text { mais força a partir de 1999, abrindo } \\
& \text { um novo ciclo, gerou uma nova } \\
& \text { aliança das classes dominantes e um } \\
& \text { novo lugar para o campo no projeto } \\
& \text { de capitalismo brasileiro, fase que } \\
& \text { está nesse momento em plena } \\
& \text { vigência e força (Fonec, 2012, p. 5). }
\end{aligned}
$$

Foi nessa conjuntura que o MEC aprovou o Curso de Educação do Campo na UFMS no ano 2013 com previsão de receber os acadêmicos para iniciar o ano letivo no segundo semestre do mesmo ano, porém, o Estado brasileiro, por meio de suas instâncias educacionais, não conseguiu organizar a contratação de docentes através de concurso público nem mesmo oferecer a estrutura física adequada aos novos alunos. Esse seria o primeiro fato que comprova a inoperância estatal em organizar a formação de professores do campo em Mato Grosso do Sul (MS).

\section{Características do curso de Licenciatura em Educação do Campo da UFMS}


Cabe mencionar que a LEDUCAMPO tem como objetivo “... proporcionar reflexão e debate sobre o fazer político-pedagógico nas escolas do campo considerando a diversidade do universo camponês, equacionando dificuldades de acesso e de permanência na escola" (UFMS, 2014, p. 2). Essa licenciatura tem como Marco Referencial o Materialismo Histórico Dialético, método capaz de compreender, criticar e problematizar a educação escolar rural concebida política e historicamente pelos fazendeiros, como processo educativo limitador no estado de MS.

A justificativa da criação do curso se deve ao fato de que MS enfrenta problemas com a falta de formação ou de formação inadequada de professores especialistas em educação do campo. Grande parte dos professores que atuam nas escolas do campo reside na cidade e não reconhece a necessidade de uma educação diferenciada para a população do campo “... que respeite as especificidades culturais e históricas como direito social de formação integral que considere o seu modo de viver e produzir (UFRB, 2013, p. 04).

Assim, o curso pretende ampliar o debate sobre a Educação Básica do Campo e, também, enfrentar as resistências encontradas para a sua implantação/implementação, provocadas _pelas marcas da concentração da propriedade da terra e de violentos conflitos nos campos sul-mato-grossenses.

A premência de professores que compreendam esse contexto a ser transformado, que ultrapassa as questões pedagógicas e que exige a adesão das escolas do campo como parceiras nas lutas enfrentadas pelos trabalhadores da terra. Essa formação pode ser consolidada com esse curso, assumido pela UFMS, como responsabilidade política e social. (UFMS 2014, p. 03).

A LEDUCAMPO faz um contraponto ideológico com o estado de MS onde se consolida um modelo de desenvolvimento econômico estruturado na pecuária extensiva e na monocultura, principalmente soja e milho, com vistas à exportação, em detrimento a produção de alimentos básicos para consumo interno. Essa característica é uma herança da política de créditos agrícolas e dos incentivos fiscais aos grandes latifundiários herdada dos governos militares.

A política militarista acreditava que as grandes propriedades rurais aliadas à mecanização eram o caminho para o desenvolvimento econômico no campo. Assim, formulou-se uma política fundiária direcionada apenas para os interesses da burguesia, desenvolvendo-se sob a égide da concentração de terras, de riqueza e de poder. 
A terra é um dos elementos estruturais da dominação de classe, um núcleo econômico, estruturante da sociedade, de modo dinâmico e que não somente constrói o político, o ideológico e cultural, mas também determinantes na organização social vigente. É justo na propriedade de vastas terras, que boa parte da elite sul-mato-grossense se forma, exerce seu domínio, seja originária da agricultura seja da pecuária ou mesmo de outras ramificações produtivas, de serviços, financeiras e construção civil.

A anexação de milhares de hectares de terras, que teve como principal desbravador colonos e arrendatários, a lógica do capital, gerou um processo de expulsão e expropriação de trabalhadores rurais do estado de MS, isso porque as oligarquias fundiárias deixaram de produzir gêneros alimentícios para se dedicarem a produzir soja, cana-de-açúcar, trigo, milho e também à criação de gado de corte com extensivas pastagens, atividades que exigiam um menor número de trabalhadores.

Deste modo, o campesinato sulmato-grossense é composto basicamente por: sem-terra, arrendatário, posseiro, assalariado, brasiguaios, entre outros. Com o apoio da Comissão Pastoral da Terra e de alguns sindicatos de trabalhadores rurais começaram a questionar o monopólio da terra e do poder político no estado de MS que, historicamente, representam os latifundiários e inicia a luta de resistência pelo acesso e permanência na terra com o intuito de romper com a lógica imposta pelo modelo de desenvolvimento burguês caracterizado pela exploração, expropriação e violência.

Dessa resistência e da mobilização dos trabalhadores rurais surgem às principais instituições responsáveis por planejar as ações contra o capital agrário em MS, como: O Movimento dos Trabalhadores Sem Terra (MST), a Central Única dos Trabalhadores no Mato Grosso do Sul (CUT/MS) e a Federação dos Trabalhadores na Agricultura do Estado de Mato Grosso do Sul (FETAGRI/MS). Essas, com o propósito de enfrentar o modelo excludente e "... concentracionista de renda, de terra e de capital, adotado na economia brasileira e na agropecuária, que se ancora na cultura latifundista quinhentista e que conta, historicamente, com o beneplácito do Estado" (Thomaz Jr., 2001, p. 01).

O enfrentamento dos movimentos sociais camponeses, por meio das ocupações de terras, contra o agronegócio, foi fundamental para inserir na agenda do Estado a implantação de projetos de assentamentos, pois, de outra forma, sem a pressão dos trabalhadores do campo muitas famílias não teriam seus lotes para produzir sua base material. Desse 
enfrentamento surge a necessidade de políticas que deem condições materiais para a fixação do camponês em seu território.

Desta forma, as políticas educacionais específicas para o campo foram conquistadas mediante a um processo de luta e resistência com o propósito de manter os filhos dos trabalhadores rurais em seus territórios e ampliar o acesso ao nível superior onde a taxa de escolarização é de $3,2 \%$, cinco vezes menor que a do urbano, $19,8 \%$ (INEP, 2012).

É nessa perspectiva que o Projeto Político-Pedagógico da LEDUCAMPO foi estruturado buscando conjugar a luta pelo acesso à educação superior pública com a luta contra a tutela política pedagógica elaborada pelo Estado aliada às necessidades do mercado.

Nessa Licenciatura o Estado é compreendido como uma das dimensões sociais resultante do trabalho (intercâmbio entre o homem e a natureza), que em determinado momento histórico gerou a propriedade privada. O Estado surge como o elemento organizador das relações antagônicas nas sociedades de classe. Como essa forma social de se organizar vem se perpetuando ao longo da existência humana, o Estado, que tem seu fundamento na propriedade privada, assume historicamente o controle da ordenação daquelas relações antagônicas, atendendo, portanto, aos interesses da classe dominante, conforme o modo de reprodução de cada forma social até aqui existente.

Impossível falar da formação histórica do Estado sem nos remetermos às explicações de Engels, fundador do socialismo científico, que juntamente com Marx abriu caminhos para a crítica da economia política. Engels (1982) escreveu, apoiado nos excertos de Marx, a obra "A origem da família, da propriedade privada e do Estado", onde afirma que o Estado sempre representa a força economicamente dominante ao auxiliar na subordinação dos dominados. Na sociedade escravista e asiática, primeiras formas sociais de exploração do homem pelo homem, o Estado se apresenta como organismo que protege os possuidores dos meios de produção em detrimento dos não possuidores.

Nessa linha de raciocínio, há de se concordar que o Estado é o elemento central na elaboração e execução de políticas públicas para a educação, em que o processo de reprodução socioeconômico é marcado pelas desigualdades na distribuição e no consumo, sob os auspícios do Estado. Isso porque, em nossa sociedade dividida em classes antagônicas, o Estado se caracteriza por ser um produto determinado pelas relações de produção 
marcadas pela propriedade privada. Segundo Marx (2010, p. 59-60), “... o Estado e a organização da sociedade não são, do ponto de vista político, duas coisas diferentes”, ao contrário, “... o Estado é o ordenamento da sociedade". De acordo com o autor, na mesma obra, o Estado “... repousa sobre a contradição entre vida privada e pública, sobre a contradição entre os interesses gerais e os interesses particulares."

O Estado é conceituado por Mészáros (2004) como o cooperador mais valoroso do Capital. Esse instrumento a favor da burguesia utiliza-se de várias instâncias, dentre elas a educação, para cumprir o papel que lhe cabe como aparato institucional da ordem burguesa e garantir o poder de classe. A educação, como uma das atividades necessárias à construção da vida social, situa-se na trama de mediações que a entrelaçam ao complexo da sociedade de classes.

Nesse viés, que a LEDUCAMPO vem travando, desde sua criação, dialogando com os gestores da UFMS na expectativa de que os mesmos cumpram com o acordo firmado com o MEC por meio da Portaria $n^{\circ} 72$, de 21 de dezembro de 2012, que prevê a liberação de recursos da matriz orçamentária da UFMS, para a execução de despesas com contratação de serviços de pessoa jurídica, locação de veículos, material de consumo, material permanente, alimentação, hospedagem, passagens e diárias para atender às necessidades de continuidade, ampliação e realização de etapas do Curso de Licenciatura Educação do Campo.

Tal compromisso está fora da agenda da reitoria da UFMS desde o ano de 2015, quando a referida instituição não abriu o processo de entrada para novos acadêmicos por meio de vestibular específico para o curso de Licenciatura em Educação do Campo, descumprindo assim com a Portaria $\mathrm{n}^{\mathrm{o}} 72$ que exigia da Universidade o ingresso de no mínimo três turmas (2014, 2015, 2016) com 150 alunos.

Uma hipótese para essa postergação é o fato de que a licenciatura em educação do campo exige mudança de paradigmas de forma que, os professores deixam de ser meros capacitores de força de trabalho e passem a sistematizar e aprofundar os saberes, os valores e as práticas educativas que estabelecem uma dinâmica social, política e cultural com os movimentos sociais ligados a terra.

Outra questão refere-se à origem social e política dos alunos, pois, boa parte deles é militante dos movimentos sociais, como por exemplo, o Movimento dos Trabalhadores Sem Terra (MST). Esses movimentos compreendem que a radicalidade política, cultural e educativa, onde "... ser radical é agarrar as coisas pela raiz, e a raiz para o homem é o próprio 
homem" (Marx, 2005, p. 151) é o ponto de partida para a luta por uma formação de educadores do campo que garanta o acesso à riqueza de práticas que leve em consideração a sua organização social. Esse compromisso pedagógico afeta diretamente o pensamento ideológico dos gestores da UFMS que historicamente sempre estiveram ao lado do agronegócio iii.

\section{Recursos financeiros}

Para fomentar essa Licenciatura o Edital SESU/SETEC/SECADI $\mathrm{n}^{\circ} \quad 2$ assegurou a UFMS em 2013 o montante de $\mathrm{R} \$$ 600.000,00 (seiscentos mil reais), por meio de Termo de Cooperação $n^{\circ} 18832$, entre a UFMS e o FNDE/2013, o que corresponde a cerca de $\mathrm{R} \$ 4.000,00$ (quatro mil reais) por aluno ano. No entanto, esse recurso foi devolvido ao FNDE por meio do NC 700286, pois a UFMS não conseguiu implantar o curso no ano de 2013 (UFMS, 2014).

No ano de 2014, uma nova remessa de dinheiro foi enviada a UFMS no valor de $\mathrm{R} \$ 1.200 .000,00$ (Um milhão e duzentos mil reais), montante que assegura a entrada de duas turmas 2014 e 2015. A liberação de recurso da Matriz Orçamentária da UFMS, nos referidos anos atendeu ao custeio de sete etapas presenciais ou Tempo Universidade (TU) com duração de trinta dias distribuídos durante $\mathrm{o}$ ano que foi usado para hospedagem, alimentação e transporte dos alunos no campus da Universidade (UFMS, 2014).

Em cumprimento com o Edital SESU/SETEC/SECADI $\mathrm{n}^{\circ}$ 2, o MEC enviou no ano de 2015 a última parcela de $\mathrm{R} \$ \quad 600.000,00$ (seiscentos mil reais), completando um total de $\mathrm{R} \$ 1.800,00$ (Um milhão e oitocentos mil reais), recurso que deveria ser destinado à abertura de edital de vestibular para uma nova turma de acadêmicos na LEDUCAMPO. Porém, até o fim do primeiro semestre do ano de 2017 a Universidade não publicou nenhum edital nesse sentido. Cabe considerar que o colegiado juntamente com os demais professores do curso está em constante negociação com a Reitoria, a fim de que a mesma assuma definitivamente o referido curso e lance edital para a aplicação de vestibular específico, permitindo assim a continuidade dessa licenciatura.

Com a entrada de apenas 2 turmas, a LEDUCAMPO começa a ter dificuldades de completar as horas aulas para os 15 professores. Fato que propicia a precarização do trabalho docente, pois os mesmos são obrigados a buscar outros cursos para ministrar aulas com a finalidade de completar a carga horária exigida. 
Aliás, uma das hipóteses que temos a respeito da implantação do curso de licenciatura do campo na UFMS foi assegurar a contratação de 15 professores, por meio do PROCAMPO, para serem distribuídos em outros cursos, caso a LEDUCAMPO não tenha continuidade, amenizando assim, os problemas que a Universidade enfrenta com a escassez de professores.

No momento em que a UFMS deixa de abrir edital para realização de vestibular específico para a licenciatura em questão, ela deixa de cumprir seu objetivo que é "Desenvolver, difundir e socializar o conhecimento por meio do ensino, da pesquisa, da extensão e da prestação de serviços e promover a formação integral e permanente dos cidadãos" (UFMS, 2017, $\mathrm{s} / \mathrm{p})$.

Essa omissão, não contribui para reduzir a taxa de analfabetismo no campo, que segundo o IBGE (2012), é três vezes maior do que na cidade, ou seja, enquanto o meio urbano possui uma população não alfabetizada de $8,6 \%$ no campo essa população é de $23,7 \%$.

No que se refere à formação de professores, convém ponderar, que o acesso dos docentes do meio rural à educação superior é precário. Segundo números da Pesquisa Nacional por Amostra de Domicílios (PNAD) de 2007, $61 \%$ dos docentes que atuam no ensino fundamental e médio do campo não apresentam formação de nível superior. Esse montante equivale a 178 mil professores sem formação adequada (Molina \& Sá, 2011).

Nesse sentido, o que se materializa na manutenção ou extinção do curso da LEDUCAMPO é a relação entre o Estado, organismo responsável pela oferta de educação pública, com os movimentos sociais ligados à terra, que mediante a sua mobilização e resistência, conquistaram a educação que pretende suprir as necessidades educacionais dos trabalhadores do campo.

Enquanto esses movimentos sociais conquistam leis e programas para atender seus interesses, essas mesmas leis e programas não dão conta de suprir as necessidades dos camponeses, pois, encontram barreiras financeiras, concessões políticas e ideológicas para que as ações sejam implementadas ou no caso da LEDUCAMPO tenha continuidade.

Apesar da UFMS não sinalizar a abertura de edital para a entrada de mais uma turma e também não propor a incorporação efetiva da LEDUCAMPO no quadro de cursos, acreditamos que os envolvidos nesse processo, sejam movimentos sociais, sejam docentes e alunos, devem continuar elaborando estratégias de resistência até o momento em que a reitoria da UFMS cumpra com 
sua parte do acordo firmado com o MEC, pois, essa formação pode contribuir para amenizar a desigualdade histórica que se traduz na extrema fragilidade pedagógica das escolas no meio rural (Molina, 2015).

Frigotto (2011) acredita que a omissão da Universidade Pública em ampliar a educação do campo é decorrente da estratégia dos organismos internacionais e do Estado brasileiro que por um lado incentiva a criação de políticas afirmativas com o propósito de desviar o foco das lutas que pretende a reestruturação do ensino superior público e de outro retira a autonomia universitária, reduz as verbas destinadas ao custeio dos cursos. Esse desmonte tem sido implantado explicitamente por meio de critérios estabelecidos pelo mercado “... e de diversas estratégias de privatização por dentro das instituições, através de perversos mecanismos de captação dos recursos via mercado, retirando cada vez mais do Estado a obrigação completa de seu financiamento" (Molina, 2015, p. 154).

O FONEC (2013) acredita que existe no Brasil uma política de "empresariamento" da educação através da entrega da gestão dos recursos públicos e das instâncias públicas de educação às Organizações Sociais (OS). Que na realidade representam os interesses do capital em seus variados setores, financeiro industrial e midiático. As fundações criadas por esses grupos retiram toda a responsabilidade de oferta da educação pública do Estado brasileiro e transferem aos docentes e alunos todos os encargos do processo de escolarização.

De acordo com Cavalcante (2010):

"O paradoxo talvez, é que a
"educação do campo" ao alcançar o
universo retórico e legalista das
políticas educacionais brasileiras já
no século XXI pode não estar de fato
sendo apropriada pelos
(significativos) pedaços do rural que
não se encontram em "movimento"
(este rural ainda sob a lógica da
produção capitalista, muitas vezes
inerte ao mundo de lutas e labutas
dos movimentos sociais em
diferentes cantos do Brasil nos
últimos vinte anos)" (Cavalcante,
2010, p. 01).

Outro ponto que pode inviabilizar os projetos político-pedagógicos das licenciaturas em educação do campo é a possibilidade de retorno às pautas da educação rural voltada para a formação técnica esvaziada de conceitos filosóficos, históricos e sociais visando apenas atender aos interesses do agronegócio.

\section{Considerações finais}

Analisamos nesse texto como se deu o processo de implantação do curso de Licenciatura em Educação do Campo da Universidade Federal de Mato Grosso do Sul e apresentamos as dificuldades para sua manutenção e expansão. Até o fim das 
argumentações presentes, o curso não conseguiu junto à Universidade elaborar e publicar edital para chamada de novos acadêmicos, o que, certamente possibilitaria a manutenção da LEDUCAMPO na grade de cursos regulares da UFMS.

Acreditamos que a morosidade do Estado e de suas Instituições educacionais em desenvolver ações em prol da licenciatura em foco, se deve as políticas de caráter neoliberais que reduzem as verbas destinadas à expansão dos cursos, o que afeta diretamente a autonomia das universidades.

Porém, os fatores ideológicos decorrentes das características pedagógicas do curso, que tem na luta de classes o seu principal ponto de reflexão como o principal entrave para a expansão da LEDUCAMPO. Esse tipo de projeto, em um estado como do MS ligado ao agronegócio, não pode permanecer na pauta do Estado.

Assim, podemos concluir que estamos longe de uma política de formação de professores do campo, que reflita sobre as necessidades dos trabalhadores do campo. Esse distanciamento reflete nas escolas localizadas no campo, pois, sem um grupo de gestores e professores, que compreendam o contexto da luta dos trabalhadores rurais, não há possibilidade de sensibilizar os gestores municipais e estaduais para que se inclua na pauta do Estado um debate sobre a necessidade de se pensar ações concretas para a educação dos povos camponeses.

\section{Referências}

Arroyo, M. G. (2012). Formação de Educadores do Campo. In Caldart, R. S. (Org.). Dicionário da Educação do Campo (pp. 359-367). Rio de Janeiro, RJ, São Paulo, SP: Escola Politécnica de Saúde Joaquim Venâncio, Expressão Popular.

Brasil (2002). Ministério da Educação. Secretaria de Educação Continuada, Alfabetização e Diversidade. Resolução CNE/CEB n. 1, de 3 de abril de 2002. Institui as diretrizes operacionais para a educação básica nas escolas do campo. Diário Oficial da União, Brasília, DF, 9 de abril de 2002. Seção 1.

Brasil (2012). Diário Oficial. 05-09-2012. Recuperado de:

https://www.jusbrasil.com.br/diarios/DOU/ 2012/09/05/Secao-.1.

Brasil (2012). Edital de Seleção $n^{\circ}$ 02/2012- SESU/SETEC/SECADI/MEC de 2012. SESU/SETEC/SECADI/MEC. Chamada Pública para seleção de Instituições Federais de Educação Superior. Recuperado de: http://portal.mec.gov.br/index.php?option= com_docman\&view=download\&alias $=115$ 6 9-minutaeditais-selecao-ifesifets03092012\&category_slug=setembro-2012pdf\&Itemid=30192.

Cavalcante, L. (2010). Das políticas ao cotidiano: entraves e possibilidades para a educação do campo alcançar as escolas do rural. Ensaio, 18(68), 549-564. 
Engels, F. (1982). A origem da família, da propriedade privada e do Estado. Rio de Janeiro, RJ: Civilização Brasileira.

Fonec. (2012). Notas para análise do momento atual da educação do campo. In Seminário Nacional. Brasília, DF.

Frigotto, G. (2010). Os circuitos da história e balanço da Educação no Brasil na primeira década do século XXI. In Conferência de Abertura da XXXIII Reunião Anual da Associação Nacional de Pesquisa e Pós-graduação em Educação (ANPED). Caxambu.

Frigotto, G. (2011). Prefácio. In Figuereido, E. (Org.). Ações afirmativas na Educação Superior: políticas de inclusão ou exclusão? (pp. 17-24). Bahia: UEFS Editora.

INEP. (2012). Educacenso. Brasília, DF.

IBGE. (2012). Estados. Censo.

Leite, S. P., \& Medeiros, L. S. (2012). Agronegócio. In Caldart, R. S. (Org.). Dicionário da Educação do Campo (pp. 81-87). Rio de Janeiro, RJ, São Paulo, SP: Escola Politécnica de Saúde Joaquim Venâncio, Expressão Popular.

Marx, K. (2010). Glosas Críticas Marginais ao artigo "O rei da Prússia e a reforma social. De um prussiano”. São Paulo, SP: Expressão Popular.

Marx, K. (2005). Crítica à filosofia de direito de Hegel. São Paulo, SP: Editora Boitempo.

Mészáros, I. (2004). Educação para além do capital. São Paulo, SP: Boitempo.

Molina, M. C. (2015). Expansão das licenciaturas em Educação do Campo: desafios e potencialidades. Educar em Revista, 55, 145-166. DOI: http://dx.doi.org/10.1590/0104-4060.39849
Molina, M. C., \& Sá, L. M. (2011). A Licenciatura em Educação do Campo da Universidade de Brasília: Estratégias Político Pedagógicas na formação de educadores do campo. In Molina, M. C., \& Sá, L. M. (Orgs.). Licenciaturas em Educação do Campo - Registros e reflexões a partir das experiências piloto (pp. 35-64). Belo Horizonte, MG: Autêntica Editora.

Nawroski A. (2012). Aproximações a Pedagogia da Alternância com a Escola Nova. In Anais IX ANPED Sul 2012. Recuperado de: http://www.ucs.br/etc/conferencias/index.p hp/anpedsul/9anpedsul/paper/view/3321/8 $\underline{0}$.

Palumbo, D. J. (1994). Public Policy in America - government in Action. Brace Company 1994.

Thomaz Jr. A. (2001). Desenho societal dos sem terra no Brasil (uma contribuição à "leitura" geográfica do trabalho). Revista Abra, 28(25), 773-794. Recuperado de: http://www2.prudente.unesp.br/ceget/pega dal.

UFMS. (2014). Projeto Pedagógico do Curso de Licenciatura em Educação do Campo. Campo Grande, MS.

UFMS. (2017). Missão da UFMS. Recuperado de: https://cpcs.ufms.br/institucional/missaoevisao-da-ufms/

UFRB. (2013). Projeto Pedagógico do Curso de Licenciatura em Educação do Campo com habilidades em ciências da natureza e matemática. Recuperado de: http://docplayer.com.br/8619124-Projetopedagogico-do-curso-de-licenciaturaemeducacao-do-campo-com-habilitacoesem-ciencias-da-natureza-ematematica.html. 
${ }^{\mathrm{i}} \mathrm{O}$ texto em questão foi publicado em forma de comunicação oral na XIV Jornada do HistedBR realizada na cidade de Foz do Iguaçu, no ano de 2017. O trabalho passou por revisão teórica, o que permitiu um aprofundamento de algumas categorias.

ii A Pedagogia da Alternância surgiu em meio a um grupo de camponeses no interior da França em 1935 que procuravam fomentar uma estratégia de escolarização capaz de manter os filhos vinculados à família e à propriedade. Assim, surge como uma proposta pedagógica a alternância de estudos na tentativa de ser uma proposta de educação mobilizadora, capaz de incentivar os jovens a irem à escola, sem terem que deixar o campo e a família. As primeiras experiências no Brasil aconteceram no estado do Espirito Santo em 1969 (Nawroski, 2012).

iii Ao modelo do agronegócio passa a ser contraposto o modelo agroecológico, pautado na valorização da agricultura camponesa e nos princípios da policultura, dos cuidados ambientais e do controle dos agricultores sobre a produção de suas sementes (Leite \& Medeiros, 2012, p. 87).

\section{Informações do artigo / Article Information}

Recebido em : 29/09/2017

Aprovado em: 26/10/2017

Publicado em: 30/08/2018

Received on September 29th, 2017

Accepted on October 26th, 2017

Published on August 30th, 2018

Contribuições no artigo: $O$ autor foi o responsável por todas as etapas e resultados da pesquisa, a saber: elaboração, análise e interpretação dos dados; escrita e revisão do conteúdo do manuscrito; e aprovação da versão final a ser publicada.

Author Contributions: The author was responsible for the designing, delineating, analyzing and interpreting the data, production of the manuscript, critical revision of the content and approval of the final version to be published.
Conflitos de interesse: $O$ autor declarou não haver nenhum conflito de interesse referente a este artigo.

Conflict of Interest: None reported.

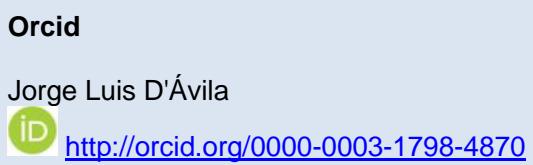

\section{Como citar este artigo / How to cite this article}

APA

D'Ávila, J. L. (2018). Política de expansão das licenciaturas em Educação do Campo: desafios para a implantação do Programa Nacional de Educação do Campo na Universidade Federal de Mato Grosso do Sul. Rev. Bras. Educ. Camp., 3(2), 633-648. DOI: http://dx.doi.org/10.20873/uft.2525-4863.2018v3n2p633

ABNT

D'ÁVILA, J. L. Política de expansão das licenciaturas em Educação do Campo: desafios para a implantação do Programa Nacional de Educação do Campo na Universidade Federal de Mato Grosso do Sul. Rev. Bras. Educ. Camp., Tocantinópolis, v. 3, n. 2, mai./ago., p. 633648, 2018. DOI: http://dx.doi.org/10.20873/uft.2525$\underline{4863.2018 \mathrm{v} 3 \mathrm{n} 2 \mathrm{p} 633}$ 